\begin{tabular}{|c|c|c|}
\hline \hline & \begin{tabular}{c} 
International Journal of Current Research in \\
Biosciences and Plant Biology \\
\hline EXCELLENT \\
PUBLISHERS
\end{tabular} & Volume $4 \bullet$ Number 6 (June-2017) ・ ISSN: 2349-8080 (Online) \\
\hline
\end{tabular}

Research Note

doi: https://doi.org/10.20546/ijcrbp.2017.406.008

\title{
Notes on a Bioculturally Associated, Endemic and Critically Endangered Raphanus Species of Jaunpur (UP), India
}

\author{
Masood Akhtar ${ }^{1}$, S. V. Singh ${ }^{2}$ and R. C. Srivastava ${ }^{3 *}$ \\ ${ }^{1}$ Department of Botany, Shibli National College, Azamgarh, Uttar Pradesh-276 001, India \\ ${ }^{2}$ Department of Botany, Shri Murli Manohar Town Post Graduate College, Ballia, Uttar Pradesh 277 001, India \\ ${ }^{3} 48 A / 14 A$, MZH Road, New Katra, Allahabad-211 002, India
}

*Corresponding author.

\section{Abstract}

The paper throws light on a bio-culturally associated species of Raphanus which is being described here as a new species viz., Raphanus jaunpurensis Massod et al.

\section{Article Info}

Accepted: 01 June 2017

Available Online: 06 June 2017

Keywords

Critically endangered

Raphanus jaunpurensis

\section{Introduction}

In Jaunpur district of Uttar Pradesh of Indian Union, an endemic radish has been associated with the culture of the people of the district, since remote epoch. There is a system of sending gifts by the parents/brothers to the married daughters on the occasion of Khichdi (Makar-Sankranti) festival. One of the most important Khichdi gift items has been the typical giant radish which is available in the markets of Jaunpur City and its suburbs only. This radish has been growing only in Jamaitha village of the Jaunpur district. A scrutiny of the relevant literature (Sharma and Balakrishnan, 1993; Hooker and Thompson, 1872; Srivastava, 2006), and websites, scrutiny of the CAL, LBW, BSA, DUTHIE, K, E revealed it to be an undescribed taxon. Hence the same is being described here as under as a new species:
Raphanus jaunpurensis Masood Akhtar, S.V. Singh \& R. C. Srivast., Sp. Nova (Figs. 1-5)

Holotype: S.V. Singh \& R.C.Srivast. 19 , dated $15^{\text {th }}$ January 2007 (CAL).

Allied to Raphanus sativus but significantly differs in size, weight and taste of the roots. All aerial parts like leaves, inflorescence, fruits and stems are also significantly larger than $R$ sativus. But seeds are smaller (than $R$ sativus) and dull in colour.

Plants erect, stout, herbaceous, turning ligneous on maturity, up to $180 \mathrm{~cm}$ (or more) high above ground (Figs. 1-2). Tap roots white, stout, up to $56 \mathrm{~kg}$ in weight; cylindrical, up to $210 \mathrm{~cm}$ or more in length, up to $75 \mathrm{~cm}$ in circumference, rarely sub-globose (Fig. 3). Leaves roughly pilose, c. $90 \times 9 \mathrm{~cm}$, lyrate-pinnatipartite, with 
sinuate-dentate segments, variable, 3-11 jugate, upper ones entire or dentate, sessile or sub-sessile, dark green, turning yellow on maturity, rough (pilose); uppermost lobe obovate, broadest. Racemes white, pedicels up to
$25 \mathrm{~cm}$ long. Flowers white; sepals greenish yellow. Petals 4, obovate, white; stamens yellow; pods up to $1 \times 7 \mathrm{~cm}$, long-beaked; seeds subglobose, uniseriate, dull gray in colour, smaller than $R$. sativus.

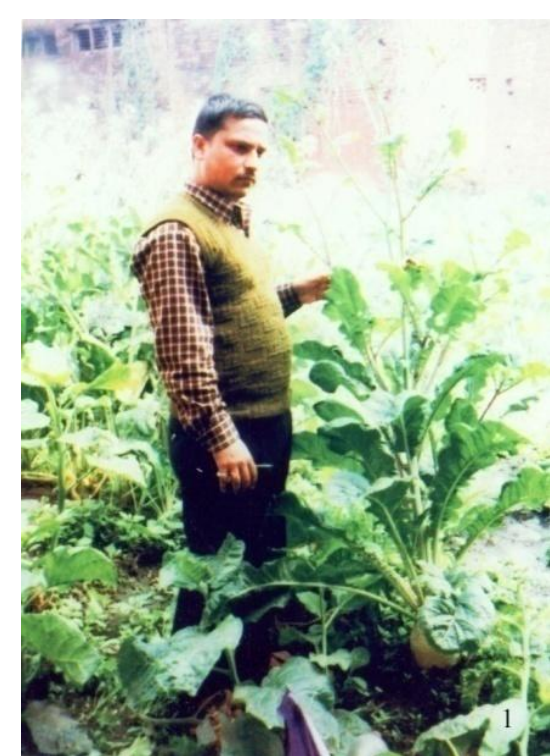

Fig. 1

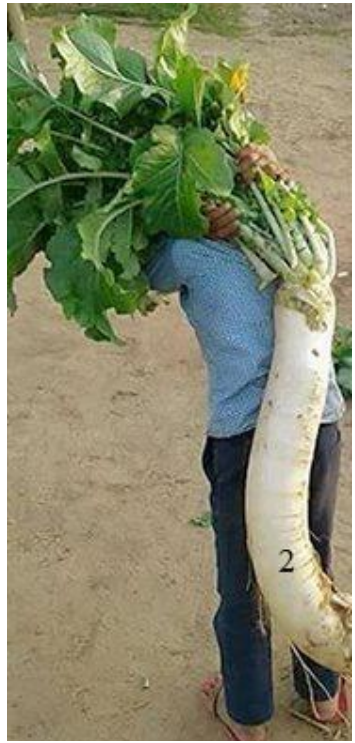

Fig. 2

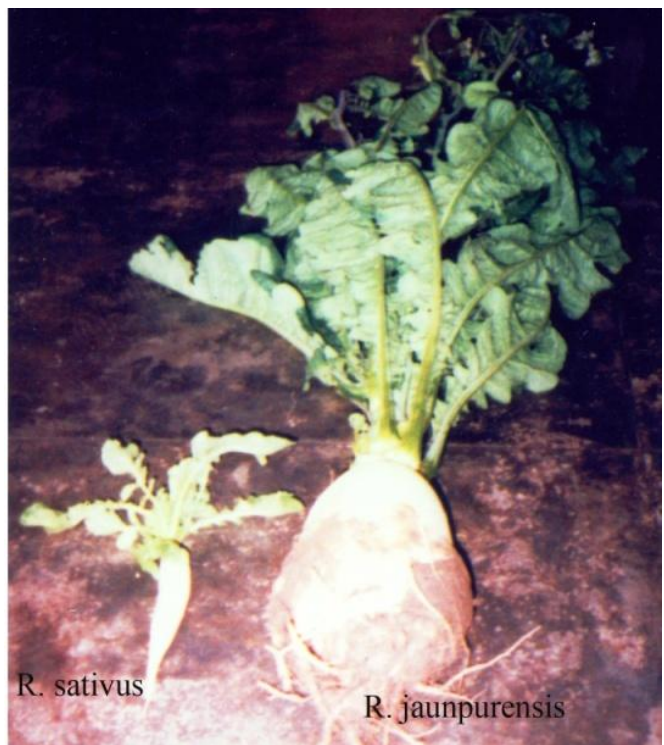

Fig. 3

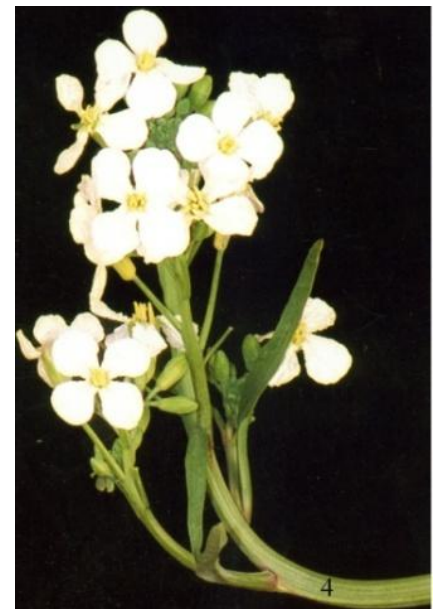

Fig. 4

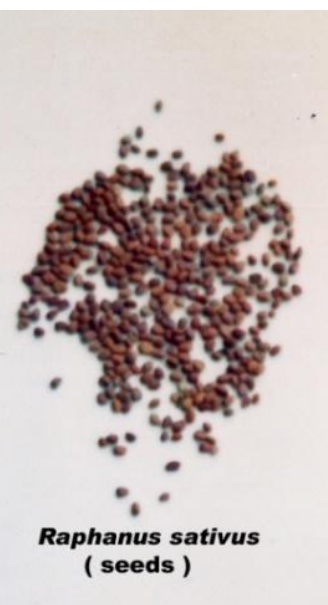

( seeds )

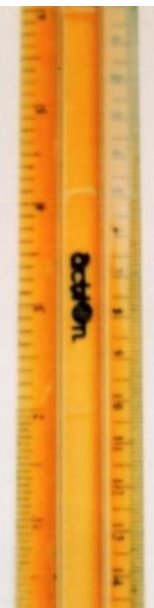

Fig. 5

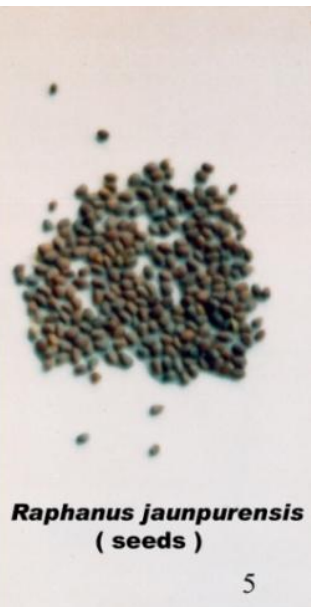

5

Figs. 1-6: (1) R. jaunpurensis: Habit; (2) Uprooted plant showing size of normal root; (3) R.sativus and $R$. jaunpurensis (sub-globose root); (4) R. jaunpurensis: flowering branch; (5) Seeds of $R$. sativus and $R$. jaunpurensis; (6) Diakon, Indian Radish (R. sativus).

Flowering / Fruiting: February-March.

Habitat: Along banks of Gomti River.

Vernacular names: Newar Murai, Newar Mooli (Hindi), Giant Radish (Eng.)

Etymology: The specific epithet is based on the district (Jaunpur) of the 'Type Locality'.
Uses: The giant roots weighing up to $56 \mathrm{~kg}$, are sent as one of the important gift items of "Khichdi Gift" from parents family to their married daughters. Root's taste is watery sweetish; eaten as salad; also pickled in various ways by the local women.

Distribution: India: Uttar Pradesh; Jaunpur District (village Jamaitha). Endemic and critically threatened (CR). Earlier found at Khasanpur, Baluaghat, Tadtala, 
Pandariba, Muftimohalla, Mulla tola localities; also recorded from Naupedva locality -cult.).

Notes: Natural populations are getting depleted at an alarming rate, from its type locality (Jamaitha locality near Jaunpur in Uttar Pradesh, India).

Conservation: No attempt has been made so far.

\section{Conflict of interest statement}

Authors declare that they have no conflict of interest.

\section{Acknowledgement}

Authors are grateful to the people of Jaunpur district for sharing the information. Thanks are also due to Dr. Rashmi Dube, Scientist D, BSI, Pune for providing copies of old literature.

\section{References}

Hooker, J.D., Thompson, T., 1872. In J.D. Hooker, Flora of British India, 1: 166. London.

Sharma, B.D., Balakrishnan, N. P., 1993. Flora of India, 2: 145. BSI, Kolkata, India.

Srivastava, R.C., 2006. Plant Resources of Uttar Pradesh. Oriental Enterprises, Dehradun, India.

\section{Websites}

https://www.youtube.com/watch?v=GRbBCBBUKgI https://www.youtube.com/watch?v=NLb2d9dutU0 www.jaunpurcity.in

www.jagran.com/uttar-pradesh/jaunpur-10140906.html www.patrika.com/.../jaunpur/now-effected-of-famousradish-of-jau...

www.hamarajaunpur.com

https://www.facebook.com/maashitla/posts/3464083021 03766

www.greenecosystem.in/buynsell/radish-mooli/jaunpur

\section{How to cite this article:}

Akhtar, M., Singh, S. V., Srivastava, R. C., 2017. Notes on a bioculturally associated, endemic and critically endangered Raphanus species of Jaunpur (UP), India. Int. J. Curr. Res. Biosci. Plant Biol. 4(6), 74-76. doi: https://doi.org/10.20546/ijcrbp.2017.406.007 